\title{
Serological and molecular characteristics of Vibrio vulnificus biotype 3: evidence for high clonality
}

\author{
Naiel Bisharat, ${ }^{1} \dagger$ Carmen Amaro, ${ }^{2}$ Belén Fouz, ${ }^{2}$ Amparo Llorens ${ }^{2}$ \\ and Daniel I. Cohen ${ }^{1}$ \\ ${ }^{1}$ Department of Epidemiology and Preventive Medicine, School of Public Health, Sackler \\ Faculty of Medicine, Tel Aviv University, Ramat Aviv, Israel \\ ${ }^{2}$ Departamento de Microbiologia y Ecologia, Campus de Burjassot, Universidad de Valencia, \\ Valencia 46100, Spain
}

Correspondence

Naiel Bisharat

bisharat_na@clalit.org.il

Received 26 October 2006

Revised 26 November 2006

Accepted 6 December 2006

\begin{abstract}
Vibrio vulnificus biotype 3 has been implicated as the causative pathogen of an ongoing disease outbreak that erupted in Israel in 1996. Recent work based on multi-locus sequence typing (MLST) showed that $V$. vulnificus biotype 3 is genetically homogeneous. The aim of this study was to investigate the existence of subpopulations within this homogeneous biotype by characterizing the surface antigens and analysing the sequence diversity of selected outer-membrane protein (OMP)-encoding genes. Rabbit antisera were prepared against biotype 1, 2 and 3 strains. The results of the slide-agglutination test, dot-blot assay (using fresh and boiled cells), and immunoblotting of lipopolysaccharides (LPS) and OMPs were evaluated. By slide-agglutination and dot-blot assays all biotype 3 strains agglutinated with the selected biotype 3 strain. This homogeneity was supported by immunoblot analysis of the LPS. Analysis of OMP patterns revealed that all three biotypes share a considerable number of common bands that are antigenically related. Cluster analysis of DNA sequence data from selected OMP-encoding genes showed that biotype 3 strains form a genetically distinct and homogeneous clone. The homogeneity of surface antigens and the lack of any sequence diversity among both housekeeping and OMP-encoding genes reaffirms the highly clonal nature of biotype 3 and suggests that it has only recently descended from the parent population of $V$. vulnificus.
\end{abstract}

\section{INTRODUCTION}

Vibrio vulnificus is considered the major cause of seafoodrelated deaths, with high fatality rates, especially among immunocompromised hosts (Oliver, 1989). The bacterium also causes a fish disease designated vibriosis, causing considerable economical losses in European eel culture (Amaro et al., 1992b). The species has been subdivided into three biotypes based on differences in biochemical, serological and molecular traits as well as host range (Bisharat et al., 1999; Blake et al., 1979; Dalsgaard et al., 1996; Tison et al., 1982). Worldwide, human disease is

Part of this work was done at the Nuffield Department of Clinical Laboratory Sciences, University of Oxford, Oxford, UK.

tPresent address: Department of Medicine, section D, Ha'Emek Medical Center, Afula 18101, Israel.

Abbreviations: MLST, multi-locus sequence typing; OMP, outermembrane protein.

The GenBank/EMBL/DDBJ accession numbers for the vuuA sequences reported in this paper are D0973529, D0973530 and D0.980539; for the wcvl sequences, D0980540 and D0980541; for the wza sequences, D0980542 and D0980543; and for the ompU sequences, DQ.980544, DQ.980545 and D0.980546. almost entirely caused by biotype 1 strains, while biotype 2 has been mainly associated with disease in eels and rarely affecting humans, mainly by the most virulent of all biotype 2 serovars, serovar E (Dalsgaard et al., 1996). Biotype 3 is geographically restricted to Israel, where it caused a serious outbreak of wound infections and bacteraemia among fish farmers and consumers of Tilapia fish cultivated in inland fish farms (Bisharat et al., 1999). To date, biotype 3 has been the only variant isolated from human disease cases in Israel.

Several molecular techniques have been applied in an attempt to better characterize this emerging pathogen (biotype 3). By pulsed field gel electrophoresis (PFGE) the strains were non-typable (Bisharat et al., 1999). PCR-RFLP (restriction fragment length polymorphism) of the cytotoxin-haemolysin gene showed that all biotype 3 strains were indistinguishable and distinct from biotypes 1 and 2 (Bisharat et al., 1999). Similar results were obtained using multi-locus enzyme electrophoresis (Gutacker et al., 2003). Recent work, based on multi-locus sequence typing (MLST) data revealed that biotype 3 is a recombinant clone that evolved by the hybridization between two populations (Bisharat et al., 2005). The analysis also showed that all the 
strains belonging to this clone were genetically uniform among all 10 housekeeping genes analysed.

The fundamental concept behind MLST is to analyse DNA sequence diversity within housekeeping genes encoding enzymes involved in intermediary metabolism, which are not subject to any unusual selective forces, and diversify slowly by the random accumulation of neutral mutations, and therefore better reflect the genetic population structure of the species (Maiden et al., 1998). Alternatively, the competition between hosts and their pathogens offers clear opportunities for selection to play a prominent evolutionary role. Thus, many pathogens show antigenic surface variations as an adaptation mechanism to evade the immune system and successfully colonize host tissues (Parmley et al., 1994; Renia et al., 1997). Nucleotide sequence analysis and serological characterization of outermembrane proteins (OMPs) may provide insights into the substructure of a homogeneous lineage (based on nucleotide sequence analysis of housekeeping genes) and may identify different subpopulations with an epidemiological interest.

The aim of the present work was to characterize the surface antigens, lipopolysaccharide (LPS) and OMPs of V. vulnificus biotype 3 and to analyse the sequence diversity of selected OMP-encoding genes.

\section{METHODS}

Bacterial isolates and culture media. The study collection consisted of 41 isolates of $V$. vulnificus, representing all three biotypes: biotype $1(n=18)$, biotype $2(n=4)$ and biotype $3(n=19)$. The list of isolates and their sources is shown in Table 1. Strains were routinely cultured in Trypticasein Soy Agar (TSA) or Broth (TSB) (Pronadisa) supplemented with $0.5 \%(\mathrm{w} / \mathrm{v}) \mathrm{NaCl}$ (TSA-1 or TSB-1) at $25^{\circ} \mathrm{C}$ (biotype 2) or $37^{\circ} \mathrm{C}$ (biotypes 1 and 3) for $24 \mathrm{~h}$. For the analysis of the OMPs, cells were grown in Marine Sea Water Yeast Extract (MSWYE) (Oliver \& Colwell, 1973) for $24 \mathrm{~h}$. MSWYE is a medium that provides cells enough iron-restriction conditions to express iron-regulated OMPs (Esteve-Gassent \& Amaro, 2004). Strains were stored in Marine Broth (Difco) plus $20 \%$ (v/v) glycerol at $-80^{\circ} \mathrm{C}$.

Antisera. Anti-biotype 1, 2 and 3 rabbit sera were prepared by intravenous injection of New Zealand rabbits with formalin-killed cells from selected strains (ATCC 27562, biotype 1; CECT 4604, biotype 2, serovar E; and VV12, biotype 3) (see Tables 1 and 4) according to the procedure described by Sorensen \& Larsen (1986). One week after the last injection, the rabbits were bled from the ear vein. All sera were stored in aliquots and frozen at $-80^{\circ} \mathrm{C}$ until used.

\section{Serological testing}

Slide-agglutination assay. The slide-agglutination assay was performed by mixing $20 \mu \mathrm{l}$ of a cell suspension in sterile saline solution (SS, $0.9 \% \mathrm{NaCl}$, pH 7.4) $\left(10^{9}\right.$ c.f.u. $\left.\mathrm{ml}^{-1}\right)$ with $20 \mu \mathrm{l}$ of serial twofold dilutions of anti-biotype 1,2 and 3 serum (Amaro et al., 1992b). The agglutination assay was performed using fresh (thermolabile antigens) and boiled (at $100{ }^{\circ} \mathrm{C}$ for $2 \mathrm{~h}$; thermostable antigens) cell suspensions. A distinct and immediate agglutination was defined as positive. Agglutination titre was recorded as the reciprocal of the highest serum dilution giving a positive reaction.
Dot-blot assay. Dot-blot analysis was performed using thermolabile and thermostable antigens as previously described (Cipriano et al., 1985). Briefly, $1 \mu \mathrm{l}$ volumes of antigens were dotted onto cellulose membranes $(0.5 \mu \mathrm{m}$; Bio-Rad) and blocked for $1 \mathrm{~h}$ with $3 \%(\mathrm{w} / \mathrm{v})$ skimmed milk in Tris-buffered saline (TBS) $(50 \mathrm{mM} \mathrm{Tris/HCl}$, $\mathrm{pH}$ 7.4). After washing twice with TBS supplemented with $0.05 \%$ Tween 20 (TBS-T), membranes were incubated for $1 \mathrm{~h}$ with serial dilutions from $1: 1000$ to $1: 64000$ of anti-biotype 1,2 and 3 sera in TBS containing $1 \%$ gelatin (TBS-1). After washing again, membranes were incubated with goat anti-rabbit immunoglobulin $\mathrm{G}$ conjugated with alkaline phosphatase (Bio-Rad) diluted at $1: 3000$ in TBS-1 for $1 \mathrm{~h}$. Specific antigen-antibody binding was detected by colour development with the substrate solution. Escherichia coli JB101 was used as a negative control. Serum titre was calculated for each antigen as the reciprocal of the lowest antibody dilution giving a similar response to that of the negative control.

Outer-membrane antigens. OMP and LPS samples were obtained from $24 \mathrm{~h}$ bacterial cultures in MSWYE medium as previously described (Amaro et al., 1992a; Biosca et al., 1993). Briefly, at midexponential phase the bacterial cells were harvested and disrupted by exposing to distilled water. The cell envelopes were collected by centrifugation at $30000 \mathrm{~g}$ for $30 \mathrm{~min}$ and treated with a solution of Sarkosyl (sodium lauroyl sarcosinate) at $0.55 \%(\mathrm{w} / \mathrm{v})$ for $10 \mathrm{~min}$. After centrifugation at $18000 \mathrm{~g}$ for $2 \mathrm{~h}$ (Biosca et al., 1993), pellets were resuspended in distilled water. Protein concentration was measured by the Lowry method and adjusted to $1 \mathrm{mg} \mathrm{ml}^{-1}$. Samples were mixed $(1: 1)$ with $2 \times$ electrophoresis final sample buffer (FSB) (Laemmli, 1970), boiled for $5 \mathrm{~min}$ and stored at $-20^{\circ} \mathrm{C}$. LPS extractions were prepared from whole-cell lysates according to the method of Hitchcock \& Brown (1983) as modified by Amaro et al. (1992a). After proteinase $\mathrm{K}$ treatment (Boehringer Mannheim), samples were mixed (1:1) with $2 \times \mathrm{FSB}$ and boiled for $5 \mathrm{~min}$.

SDS-PAGE and immunoblotting. LPS and OMP samples were analysed by SDS-PAGE (Laemmli, 1970) and immunoblotting according to previously described methods (Amaro et al., 1992a; Biosca et al., 1993; Esteve-Gassent \& Amaro, 2004). OMPs were visualized by both Coomassie brilliant blue staining and immunostaining with anti-OmpU or anti-VuuA sera (Esteve-Gassent \& Amaro, 2004), and LPS bands by immunostaining with anti-biotype serum (Amaro et al., 1992a). Prior to immunostaining, protein and LPS bands were transferred from the polyacrylamide gels to nitrocellulose sheets $(0.45 \mu \mathrm{m}$; Bio-Rad $)$ as described by Towbin et al. (1979). Blotting was done at $200 \mathrm{~mA}$ for $2 \mathrm{~h}$ in Tris/glycine/methanol transfer buffer (25 mM Tris, $192 \mathrm{mM}$ glycine, $\mathrm{pH}$ 8.3, and $20 \%$ methanol). The immunological staining of LPS and OMPs was performed using a 1:1000 dilution of rabbit anti-biotype 1,2 and 3 sera, or a 1:4000 dilution of anti-OmpU/VuuA serum, respectively (Amaro et al., 1992a; Esteve-Gassent \& Amaro, 2004). Pre-stained molecular mass markers (Kaleidoscope Prestained Standards; Bio$\mathrm{Rad})$ were used as controls.

DNA extraction. The DNeasy kit (Qiagen) was used to extract DNA with the Gram-negative bacterial protocol as recommended by the manufacturer.

Genes chosen for analysis. The following OMP-encoding genes were chosen for further analysis: $w z a$, encoding an outer-membrane lipoprotein involved in surface assembly of capsular antigen (Wright et al., 2001); ompU, encoding a major OMP (Park et al., 2006); $v u u A$, encoding the ferric vulnibactin outer-membrane receptor (Webster \& Litwin, 2000); and wcvI, encoding a glycosyltransferase involved in capsule synthesis (Smith \& Siebeling, 2003). Mutations in any of these selected genes have been related to some reduction of virulence of vibrios (Provenzano et al., 2001; Smith \& Siebeling, 2003; Webster \& Litwin, 2000; Wright et al., 2001). 
Table 1. Characteristics of the V. vulnificus isolates used in the study

\begin{tabular}{|c|c|c|c|c|c|}
\hline Isolate $^{*}$ & Biotype $\dagger$ & ST $\ddagger$ & Country & Year & Source \\
\hline ATCC $27562^{\mathrm{T}} \S$ & 1 & 3 & USA & - & Human \\
\hline C7184 & 1 & 1 & USA & - & Human \\
\hline SPRC 10213 & 1 & 4 & USA & - & Environment \\
\hline $960717-1 / 5 \mathrm{C}$ & 1 & 10 & Denmark & - & Diseased eel \\
\hline WRI & 1 & 12 & USA & - & Environment \\
\hline DAL 6-5000 (CDC 9345-95) & 1 & 18 & USA & 1995 & Human \\
\hline LOS 7318 (CDC 9038-96) & 1 & 20 & USA & 1996 & Human \\
\hline DAL 79040 (CDC 9070-96) & 1 & 21 & USA & 1996 & Human \\
\hline M06 & 1 & 32 & USA & - & Human \\
\hline LAM264 & 1 & 32 & USA & - & Human \\
\hline 99-625 DP-D8 & 1 & 38 & USA & 1999 & Shellfish \\
\hline 99-537 DP-G7 & 1 & 39 & USA & 1998 & Shellfish \\
\hline $\mathrm{I}-29$ & 1 & 47 & Japan & - & Environment \\
\hline $5 / \mathrm{I}$ & 1 & 58 & Israel & 1997 & Environment \\
\hline CCUG 38297 & 1 & 61 & Sweden & 1997 & Human \\
\hline ORL 8074 (CDC 9032-95) & 1 & 64 & USA & 1995 & Human \\
\hline $\mathrm{CH} 1603 \mathrm{O}: 8$ & 1 & 66 & Germany & - & Environment \\
\hline CCUG 47321 & 1 & 68 & Sweden & 2003 & Human \\
\hline CECT 4604 (E 86)§ & $2(\mathrm{E})$ & 6 & Spain & 1990 & Diseased eel \\
\hline CECT 4603 (E 58) & $2(\mathrm{E})$ & 6 & Spain & 1990 & Diseased eel \\
\hline NCIMB 2136 & $2(\mathrm{E})$ & 6 & Japan & 1976 & Diseased eel \\
\hline CECT 5198 & 2 (non-E) & - & Spain & 2000 & Diseased eel \\
\hline 97 & 3 & 8 & Israel & 1997 & Human \\
\hline 11028 & 3 & 8 & Israel & 1996 & Human \\
\hline VV12S & 3 & 8 & Israel & 1996 & Human \\
\hline VV32 & 3 & 8 & Israel & 1996 & Human \\
\hline VV44 & 3 & 8 & Israel & 1998 & Human \\
\hline VV50 & 3 & 8 & Israel & 1999 & Human \\
\hline 162 & 3 & 8 & Israel & 1997 & Human \\
\hline 491771 & 3 & 8 & Israel & 1997 & Human \\
\hline 407 & 3 & 8 & Israel & 1997 & Human \\
\hline 8179 & 3 & 8 & Israel & 1997 & Human \\
\hline 7356 & 3 & 8 & Israel & 1998 & Human \\
\hline 658 & 3 & 8 & Israel & 1999 & Human \\
\hline 58 & 3 & 8 & Israel & 1998 & Human \\
\hline 2321 & 3 & 8 & Israel & 1997 & Fish \\
\hline ATCC BAA-86 & 3 & 8 & Israel & 1995 & Human \\
\hline VV 7-00 & 3 & 8 & Israel & 2000 & Human \\
\hline VV 3-01 & 3 & 8 & Israel & 2001 & Human \\
\hline VV 6-02 & 3 & 8 & Israel & 2002 & Human \\
\hline VV 4-03 & 3 & 8 & Israel & 2003 & Human \\
\hline
\end{tabular}

${ }^{*}$, type strain of the species; ATCC, American Type Culture Collection; CECT, Colección Española de Cultivos Tipo; CDC, Centers for Disease Control; CCUG, Culture Collection University of Goteborg (Sweden).

$\dagger \mathrm{E}$, serovar E; non-E, non-serovar E.

$¥ \mathrm{ST}$, sequence type.

$\S$ Strains used for rabbit immunization to obtain specific antisera.

The fragments sequenced from each of these genes are shown in Table 2. Primers were designed based on conserved regions from alignment of the nucleotide sequence of these genes from the two clinical strains of $V$. vulnificus, CMCP6 (GenBank accession nos AE016795 and AE016796) and YJ016 (GenBank accession nos
BA000037 and BA000038) (Chen et al., 2003). The PCR and sequencing primers are shown in Table 3. For the wza and $w c v I$ genes, the same primers were used for PCR amplification and sequencing (in different concentrations: for PCR amplification

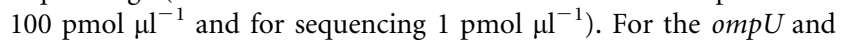


Table 2. Amplicon size and sequenced fragment of the chosen genes

\begin{tabular}{|c|c|c|c|c|c|}
\hline Gene & Product & $\begin{array}{l}\text { Size of amplified } \\
\text { fragment (bp) }\end{array}$ & $\begin{array}{l}\text { Size of sequenced } \\
\text { fragment }(b p)\end{array}$ & $\begin{array}{l}\text { Polymorphic } \\
\text { sites }(\%)\end{array}$ & $d_{\mathrm{N}} / d_{\mathrm{S}}$ ratio \\
\hline$w z a$ & $\begin{array}{l}\text { Outer-membrane lipoprotein; surface assembly of } \\
\text { capsular antigen }\end{array}$ & 550 & 297 & $19(6.4)$ & 1.3 \\
\hline ompU & Outer-membrane protein $\mathrm{U}$ (porin) & 1300 & 913 & $571(56.4)$ & 1.2 \\
\hline vuuA & $\begin{array}{l}\text { Ferric vulnibactin outer-membrane receptor } \\
\text { (iron receptor) }\end{array}$ & 2065 & 1628 & $247(15.2)$ & 1.5 \\
\hline
\end{tabular}

$v u u A$ genes, two sets of sequencing primers were used to sequence the desired size of the gene fragment. The PCR amplification, PCR product precipitation, sequencing reaction and sequencing precipitation methods were carried out as previously described for the MLST studies of V. vulnificus (Bisharat et al., 2005). The sequences were assembled using the Staden suite of computer programs (Staden, 1996). The number of polymorphic nucleotide sites and the calculation of $d_{\mathrm{N}} / d_{\mathrm{S}}$ ratio (non-synonymous/synonymous substitutions) were estimated using the program START (Jolley et al., 2001). The phylogenetic relationships between the different strains were investigated using distance matrix methods, also known as clustering algorithmic methods [neighbour-joining (NJ) tree], as implemented in MEGA (molecular evolutionary genetic analysis) (http://www.megasoftware.net) version 3.1 (Kumar et al., 2004). The phylogenetic relationships between the different strains based on sequencing of OMP-encoding genes (current study) were compared with the phylogenetic relationships based on concatenated sequences from MLST data from a previous study (Bisharat et al., 2005). For this analysis the nucleotide sequences of 10 MLST loci, making up the sequence type of each strain, were concatenated into a single (4326 bp) length of DNA representing each strain. The bootstrapping method was used to test the accuracy of the clustering. The values on the NJ tree are percentages of 500 computer-generated trees produced by randomly sampling the sequences and are shown at the nodes.

\section{RESULTS}

\section{Serological characterization}

All biotype 3 strains (six strains used for this part of the study), regardless of the antigen used, agglutinated with the antiserum obtained against the selected biotype 3 strain (agglutination titres between 64 and 128) (Table 4). Conversely, they did not agglutinate (titres $<2$ ) with antisera against the selected biotype 1 and biotype 2-serovar E strains (Table 4). Likewise, biotype 1 (ATCC 27562) and biotype 2-serovar E (CECT 4604) strains only agglutinated with the homologous antisera (titres between 64 and 128) (Table 4). As expected, the biotype 2 strain of non-serovar $\mathrm{E}$ did not agglutinate with anti-CECT 4604 (serovar E) serum (Table 4).

The results of dot-blot assays using thermostable (boiled cells) and thermolabile (fresh cells) antigens from strains of the three biotypes are also shown in Table 4. Titres for each serum, evaluated with the homologous strain, were $\geqslant 64000$, regardless of the antigen used. The anti-biotype 3 serum gave the same titres with all biotype 3 strains, including the homologous strain (Table 4). Clear crossreactions between biotypes were detected when thermolabile antigens were used (titres between 16000 and 32000 ) but not with thermostable antigens (titres $=2000)($ Table 4$)$.

OMP patterns from selected strains of the three biotypes are shown in Fig. 1. The OMP patterns of biotype 3 strains were almost identical and similar to those of the selected strains of biotype 1 and 2 (Fig. 1a). Part of the similarity was revealed by immunoblotting with specific antisera (Fig. 1b). Thus, a band that co-migrated as the protein OmpU and the other as

Table 3. Primers used for PCR amplification and sequencing

\begin{tabular}{|c|c|c|c|}
\hline \multirow[t]{2}{*}{ Locus } & \multirow[t]{2}{*}{ Use } & \multicolumn{2}{|c|}{ Name and sequence of primer } \\
\hline & & Forward $\left(5^{\prime}\right.$ to $\left.3^{\prime}\right)$ & Reverse $\left(5^{\prime}\right.$ to $\left.3^{\prime}\right)$ \\
\hline$w z a$ & $\begin{array}{l}\text { Amplification and } \\
\text { sequencing }\end{array}$ & wza-A1, ACCGTTCCCTTGAATACCCCA & wza-A2, GTTTCGCTGCACAAATCAAAGC \\
\hline ompU & Amplification & ompU-A1, ATCGCACTTTCTGTATCTGCTG & ompU-A2, AGAAGTCGTAACGTAGACCTAG \\
\hline vuuA & Amplification & VuuA-A1, ATGGCAGCTTTACGCCCAG & VuuA-A2, ATGAAGCACCAATCATACGTGG \\
\hline$w c v I$ & $\begin{array}{l}\text { Amplification and } \\
\text { sequencing }\end{array}$ & wcvI-A1, GTTGTGATTGGTGAGACGATC & wcvI-A2, CGAGATTCAACAACCACACCA \\
\hline ompU & Sequencing & ompU-S1, AAATCCAAGACGGCCTATACG & ompU-S2, AGAAGTCGTAACGTAGACCTAG \\
\hline ompU & Sequencing & ompU-S3, GGCAGATAAAATCGCTGTTGC & ompU-S4, CCCATAGTGTAAGACGCC \\
\hline vuuA & Sequencing & VuuA-S1, AGAGATGCCTGTTGTCGTTGT & VuuA-S2, CCAATTGAGCATTAGCGACCC \\
\hline vuuA & Sequencing & VuuA-S3, CAGCGAAACTATTCACAAACCG & VuuA-S4, CGAATTGTAGCCTTTTGCCAC \\
\hline
\end{tabular}


Table 4. Titres of antisera raised against selected strains of $V$. vulnificus biotypes 1,2 and 3 obtained by dot-blot and agglutination assays

The serovars are indicated in parentheses. ${ }^{\mathrm{T}}$, type strain of the species. Dot-blot titre for each antiserum and antigen combination is expressed as the reciprocal of the highest dilution of serum giving a response above the negative control. Agglutination titre for each antiserum and antigen combination is expressed as the reciprocal of the highest dilution of serum giving a positive agglutination.

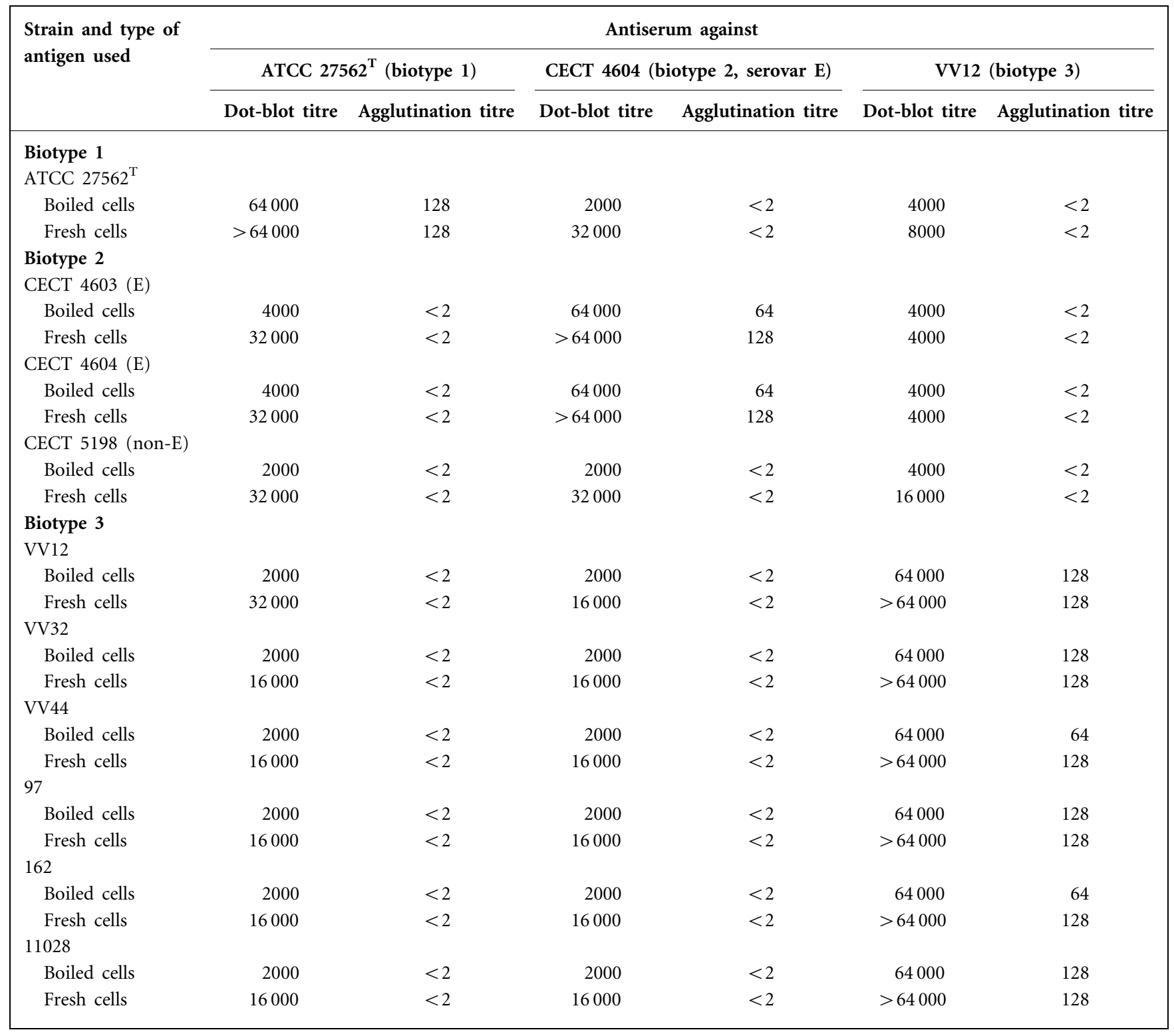

protein VuuA were identified in the OMP samples from all strains and biotypes (Fig. 1b). The band patterns of the three biotypes mainly differed in two major bands additional to OmpU, one of about $44 \mathrm{kDa}$, present in biotype 2 strain (lanes 1 and 2 in Fig. 1a) and the other of about $32 \mathrm{kDa}$, present in biotype 1 strain (lane 3 in Fig. 1a).

LPS of biotype 3 strains was visualized by immunostaining with anti-VV12 serum. All LPS samples from biotype 3 strains exhibited a ladder-like structure typical of smooth LPS (Fig. 2a). The pattern corresponding to O-antigen was clearly different from that exhibited by biotype 1 and 2 strains (Fig. 2b). Three fractions, of high, medium and low mobility, were present in the biotype 3 pattern whereas only one, of medium and of very low mobility, was present in those of biotypes 1 and 2, respectively (Fig. 2b). Finally, LPS samples from biotype 3 strains were not stained with the antisera against the selected strains of biotypes 1 and 2 (Fig. 2b). Conversely, LPS samples from selected biotype 1 and 2 isolates were stained only with their homologous antisera but not with the anti-biotype 3 serum (Fig. 2b).

\section{Estimation of sequence diversity}

The proportion of the variable nucleotides present in the gene fragments (for all 19 strains used) ranged from $6.4 \%$ 
(a)

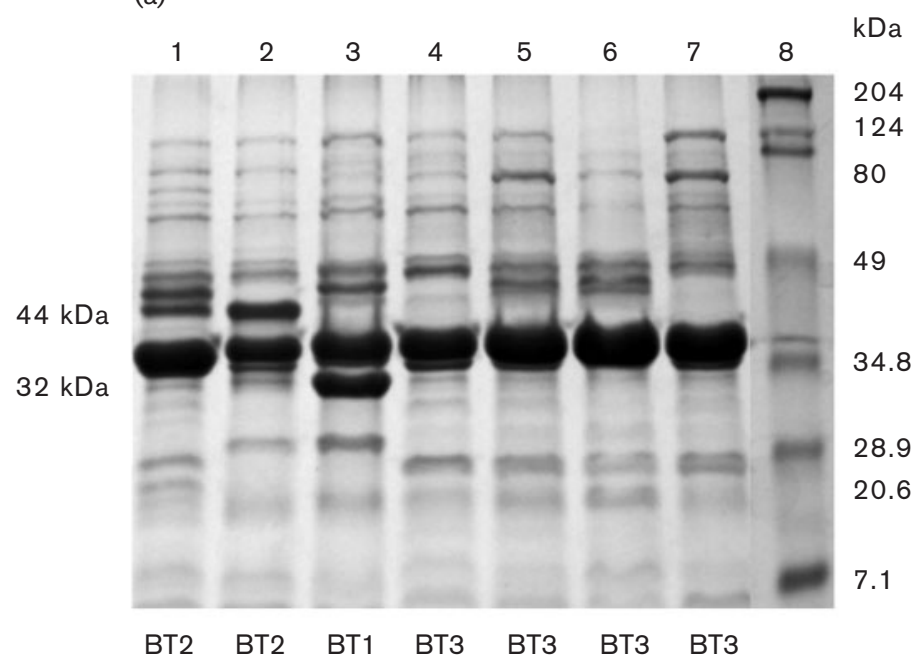

(b)

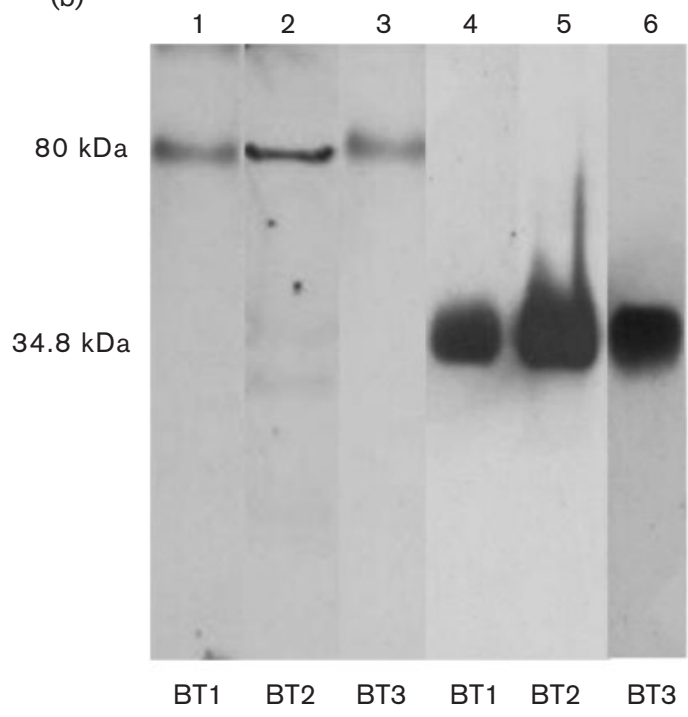

Fig. 1. (a) OMP patterns of strains of $V$. vulnificus biotypes 1, 2 and 3 grown in MSWYE and visualized by staining with Coomassie blue. Lanes: 1, CECT 5198 (biotype 2, non-serovar E); 2, CECT 4604 (biotype 2, serovar E); 3, ATCC $27562^{\top}$ (biotype 1); 4, 97 (biotype 3); 5, 11028 (biotype 3); 6, VV12 (biotype 3); 7, VV32 (biotype 3); 8, molecular mass standards (Kaleidoscope Prestained Standards, Bio-Rad). BT, biotype. (b) Nitrocellulose filters from SDS-PAGE of OMP samples of strains ATCC $27562^{\top}$ (biotype 1) (lanes 1, 4), CECT 4604 (biotype 2-serovar E) (lanes 2, 5) and VV12 (biotype 3) (lanes 3 , 6 ) immunostained with antiserum against the purified putative vulnibactin receptor, VuuA (lanes 1, 23 ), and the main OMP, OmpU (lanes $4,5,6$ ). The positions of two protein standards of 80 and $34.8 \mathrm{kDa}$ are indicated. BT, biotype.

(wza) to $56.4 \%$ (ompU) (Table 2). The proportion of nucleotide substitutions that changed the amino acid sequence (non-synonymous substitutions, $d_{\mathrm{N}}$ ) and the proportion of silent changes (synonymous substitutions, $d_{S}$ ) were calculated for each fragment. Using these data, the $d_{\mathrm{N}} / d_{\mathrm{S}}$ ratios were all above 1 (Table 2 ), suggesting that there is a selection for a change in amino acid and consistent with the concept that OMP-encoding genes are not under a neutral selection process.

Nucleotide sequence analysis revealed that all biotype 3 strains had identical sequences at each of the four genes (a)

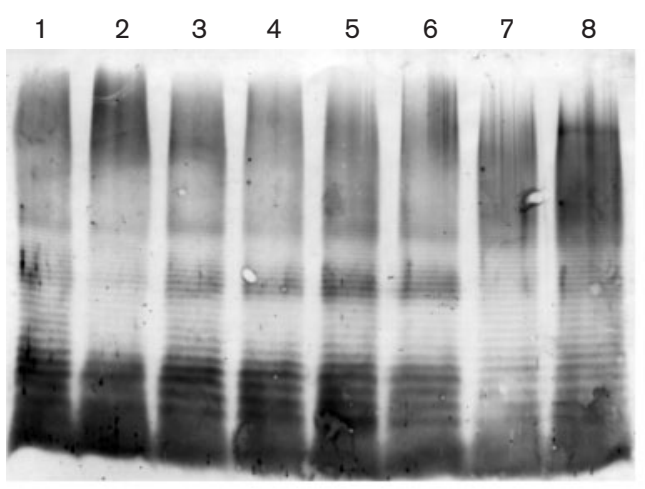

(b)

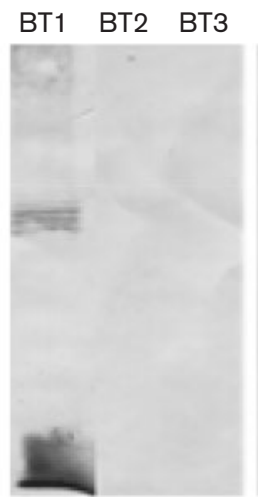

Anti-BT1 serum

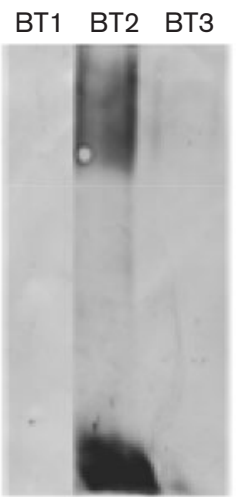

Anti-BT2 serum
BT1 BT2 BT3

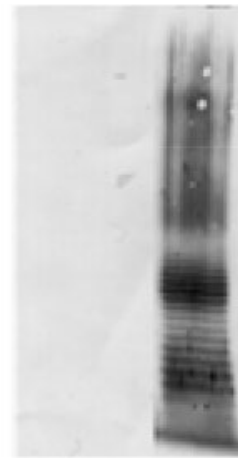

Anti-BT3 serum

Fig. 2. LPS patterns of strains of $V$. vulnificus biotypes 1,2 and 3. (a) Nitrocellulose filters from SDS-PAGE of LPS samples immunostained with anti-biotype 3 serum diluted 1:1000. Lanes: 1, 97 (biotype 3); 2, 11028 (biotype 3); 3 , VV12 (biotype 3); 4, VV32 (biotype 3); 5, 162 (biotype 3); 6, VV44 (biotype 3); 7, 58 (biotype 3); 8, ATCC BAA-86 (biotype 3). (b) Nitrocellulose filters from SDS-PAGE of LPS samples immunostained with antisera against biotype 1, 2 or 3 diluted 1:1000. Lanes: 1, ATCC $27562^{\top}$ (biotype 1); 2, CECT 4604 (biotype 2-serovar E); 3, VV12 (biotype 3). BT, biotype. 
examined. This result was in contrast to those of biotypes 1 and 2, for which almost every strain exhibited sequence diversity compared to the other strains of the homologous biotype. Cluster analysis of the individual genes produced two groups, yet the strains within the groups varied by gene (Fig. 3). It also showed that biotype 3 strains form a distinct and homogeneous clone, yet closely related to strains of biotypes 1 and 2, compatible with the OMP patterns obtained using SDS-PAGE (Fig. 1). For presentation purposes, only a subset of the strains was used for constructing the phylogenetic trees (11 biotype 1, 2 biotype 2 and 2 biotype 3 strains). For the $w c v I$ gene only nine sequences are shown; the remaining sequences were identical to the main group in the middle and for presentation purposes were taken out.

\section{Correlation with analysis from MLST loci}

Analysis of sequence data from these sites (OMP-encoding genes) showed little correlation with the analysis from MLST loci. Closely related strains (based on MLST analysis) did not exhibit similar genetic relatedness when OMPencoding genes were analysed (Fig. 3). The only exception was biotype 3, which showed a distinct pattern of sequence homogeneity among both MLST loci and OMP-encoding genes. Nevertheless, the phylogenetic analysis using MLST

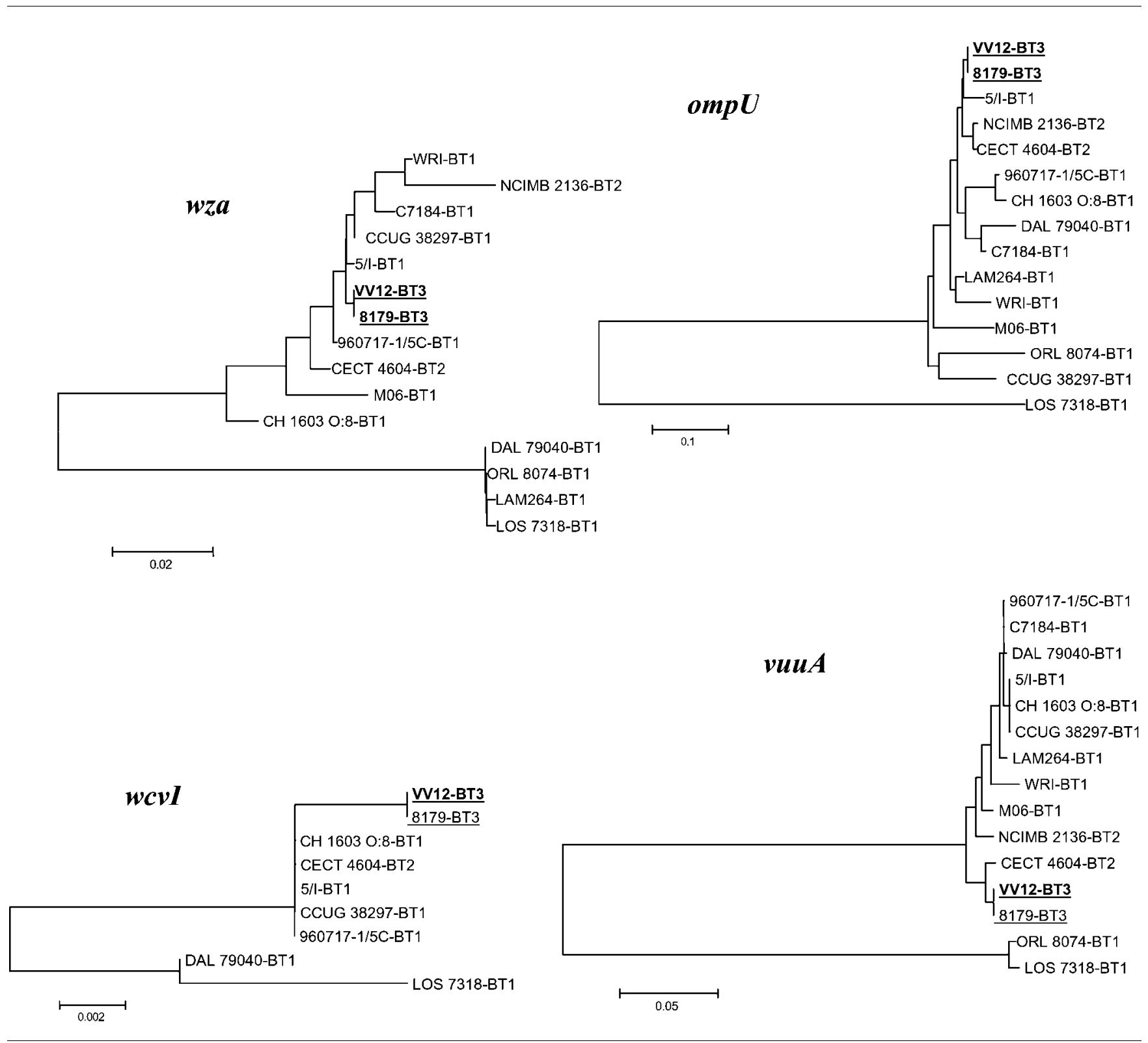

Fig. 3. Neighbour-joining tree of nucleotide sequences from four selected OMP-encoding genes. 
data placed biotype 3 in an intermediate position between the two main populations of $V$. vulnificus (Fig. 4), whereas the analysis of OMP-encoding genes grouped biotype 3 with one of the two main clusters (Fig. 3).

\section{DISCUSSION}

The present study showed that $V$. vulnificus biotype 3 expresses a homogeneous LPS and exhibits highly conserved nucleotide sequences among OMP-encoding genes. Using polyclonal antibodies raised against whole cells, slideagglutination and dot-blot assay showed that biotype 3 strains could be grouped together and be clearly distinguished from biotype 1 and 2 strains. Although agglutination titres were lower than dot-blot titres, both assays were highly discriminating, especially when boiled cells were used as antigens. Further serological characterization by immunostaining of LPS and OMP extracts showed that biotype 3 expresses a homogeneous LPS, whereas the OMP patterns of the three biotypes were related.

Analysis of DNA sequence diversity of selected OMPencoding genes showed that biotype 3 strains form a genetically homogeneous clone, yet closely related to those of biotypes 1 and 2. These findings are compatible with the OMP patterns obtained (Fig. 1), suggesting that OMPs from the three biotypes are closely related. In fact, our goal of identifying subpopulations within the homogeneous biotype 3 was not achieved.
Elements suggestive of recent evolution from the parent population of $V$. vulnificus were associated with biotype 3: the lack of any genetic diversity among both housekeeping genes (Bisharat et al., 2005) and OMP-encoding genes (present analysis), the distinct biochemical characteristics (Bisharat et al., 1999) and the clear association with disease in humans. In fact, biotype 3 and biotype 2-serovar E share some interesting similarities, most remarkably the finding that they both express a homogeneous LPS (Biosca et al., 1996 and present analysis), both are genetically homogeneous among MLST loci (Bisharat et al., 2005, Fig. 4 and unpublished data), both exhibit a distinct biochemical pattern (Bisharat et al., 1999; Tison et al., 1982) and, finally, each has a very specific niche, biotype 2 -serovar E primarily affecting eels and biotype 3 affecting only humans.

Maynard Smith et al. (Smith et al., 1993) have suggested a model where clonal lineages emerge due to the acquisition of a strong selective advantage, which allows them to rise rapidly in frequency in the population, and as the strains diverge and specialize on their respective hosts, they become more reproductively isolated, eventually creating distinct lineages. In synthesizing these observations, we hypothesize that biotype 2-serovar $\mathrm{E}$ and biotype 3 have only recently descended from the parent population of $V$. vulnificus.

To date, the homogeneous biotype 3 has been isolated only in Israel. Data suggest that it has been circulating within Israeli fish farms at least since 1981 (Bisharat et al., 1999).

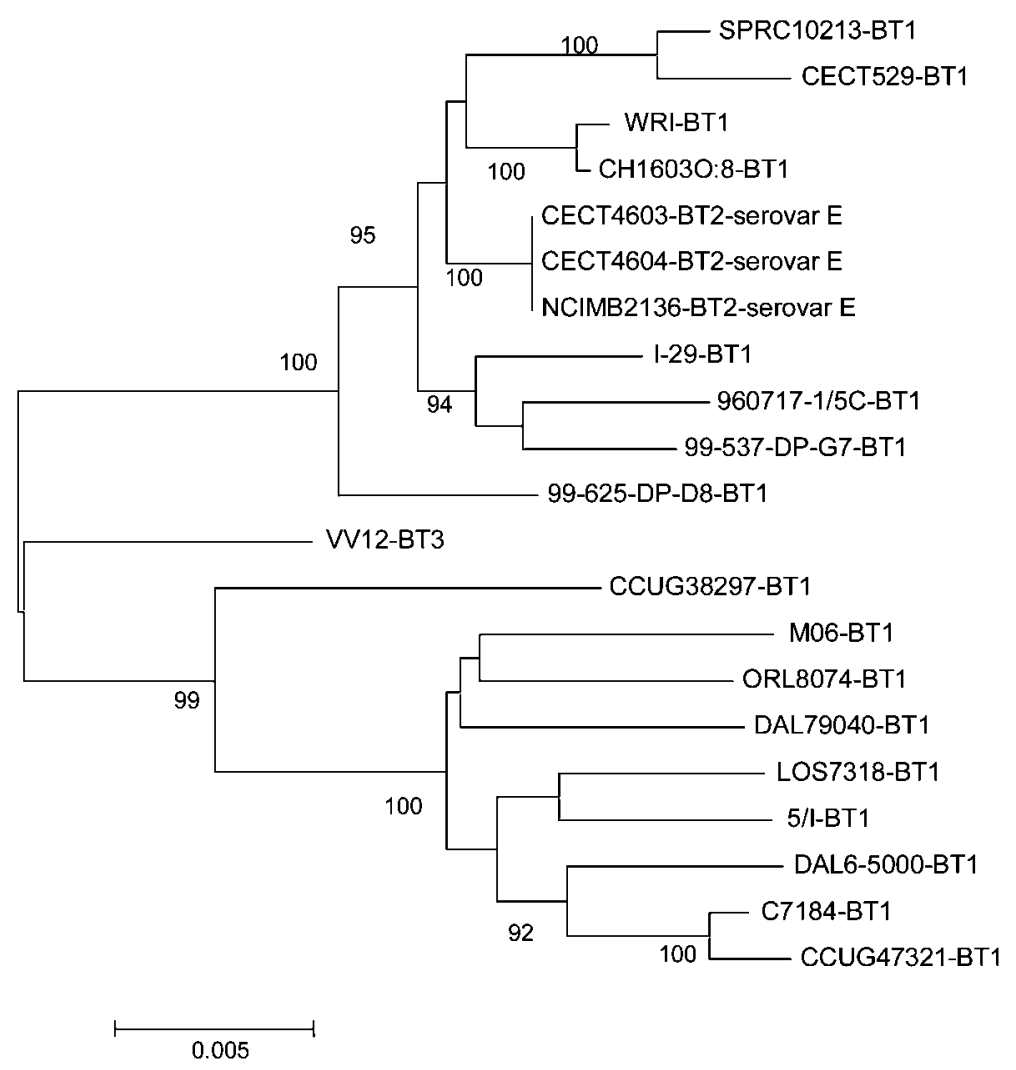

Fig. 4. Neighbour-joining tree of concatenated sequences from 10 MLST loci (housekeeping genes). All biotype 3 strains resolved into the same sequence type. For clarity only one strain is shown. 
Therefore, the exact cause for the disease outbreak in the 1990s has yet to be determined. Initially, it was suggested that changes in fish marketing procedures may have facilitated the disease outbreak (Bisharat \& Raz, 1996). However, and despite the implementation of a new fish marketing policy, disease continued (N. Bisharat, unpublished data). A possible link between regional impact of global warming on the Eastern Mediterranean basin and disease outbreak has recently been suggested (Paz et al., 2006).

In view of the trend of exporting stocks of cultured Tilapia fish (from Israel) the appearance of this virulent $V$. vulnificus biotype in other parts of the world should be considered. Interestingly, it has been speculated that the appearance of biotype 2 in European eel farms has probably occurred due to imports of carrier eels from Japan (Amaro et al., 2001), where the biotype was originally described (Tison et al., 1982).

The distinctiveness of the LPS of biotype 3 from the LPS of the other biotypes of $V$. vulnificus could be utilized for the development of rapid methods for the specific detection of this pathogen, as has been achieved for biotype 2 (Biosca et al., 1997), and for the generation of LPS-based vaccines. The use of LPS-based vaccines in humans has not been successful so far, because of either the heterogeneity of the LPS molecule or the lack of sufficient immunogenicity, although recently some promising results were reported using immunogenic protein carrier covalently linked to $O$ deacylated lipopolysaccharide (LPS) derived from Neisseria meningitidis in animal models (Cox et al., 2005). Thus far, the use of LPS-based vaccines against vibriosis in eels has not been promising and the authors suggested that LPS from $V$. vulnificus serovar $\mathrm{E}$ may not be immunogenic for eels (Collado et al., 2000). Others, however, have reported more encouraging results against other vibrios (Fukuda \& Kusuda, 1985; Salati \& Kusuda, 1985). Studies are currently under way to determine whether the LPS molecule of $V$. vulnificus biotype 3 can elicit a significant immune response in humans (N. Bisharat, unpublished data).

In summary, the present work reaffirms the highly clonal nature of $V$. vulnificus biotype 3 and suggests that it has only recently evolved from the parent population. Future studies should focus on utilizing the present data for developing rapid detection methods, inquiring whether the LPS molecule is immunogenic in humans, and determining the feasibility and the effectiveness of LPS-based vaccines in humans.

\section{ACKNOWLEDGEMENTS}

This work was supported in part by the Wellcome Trust, grant no. 067147/Z/02/Z, and by the Spanish project AGL2005-04688 from the Spanish Ministry for Education and Science (SMES). B. Fouz thanks SMES for her research contract 'Ramón y Cajal'.

\section{REFERENCES}

Amaro, C., Biosca, E. G., Fouz, B. \& Garay, E. (1992a). Electrophoretic analysis of heterogeneous lipopolysaccharides from various strains of Vibrio vulnificus biotypes 1 and 2 by silver staining and immunoblotting. Curr Microbiol 25, 99-104.

Amaro, C., Biosca, E. G., Esteve, C., Fouz, B. \& Toranzo, A. E. (1992b). Comparative study of phenotypic and virulence properties in Vibrio vulnficus biotype 1 and 2 obtained from a European eel farm experiencing mortalities. Dis Aquat Organ 13, 29-35.

Amaro, C., Fouz, B., Collado, R., Esteve-Gassent, D., MarceloNoales, E., Esteve, C., Barrera, R. \& Alcaide, E. (2001). Design and development of a vaccine against eel vibriosis caused by Vibrio vulnificus serovar E (or biotype 2) applied to intensive culture facilities (Report). Valencia: Departamento de Microbiologia y Ecologia, Universidad de Valencia, Valencia, Spain.

Biosca, E. G., Garay, E., Toranzo, A. E. \& Amaro, C. (1993). Comparison of outer membrane protein profiles of Vibrio vulnificus biotypes 1 and 2. FEMS Microbiol Lett 107, 217-222.

Biosca, E. G., Oliver, J. D. \& Amaro, C. (1996). Phenotypic characterization of Vibrio vulnificus biotype 2, a lipopolysaccharidebased homogeneous $\mathrm{O}$ serogroup within Vibrio vulnificus. Appl Environ Microbiol 62, 918-927.

Biosca, E. G., Marco-Noales, E., Amaro, C. \& Alcaide, E. (1997). An enzyme-linked immunosorbent assay for detection of Vibrio vulnificus biotype 2: development and field studies. Appl Environ Microbiol 63, 537-542.

Bisharat, N. \& Raz, R. (1996). Vibrio infection in Israel due to changes in fish marketing. Lancet 348, 1585-1586.

Bisharat, N., Agmon, V., Finkelstein, R., Raz, R., Ben-Dror, G., Lerner, L., Soboh, S., Colodner, R., Cameron, D. N. \& other authors (1999). Clinical, epidemiological, and microbiological features of Vibrio vulnificus biogroup 3 causing outbreaks of wound infection and bacteraemia in Israel. Israel Vibrio Study Group. Lancet 354, 1421-1424.

Bisharat, N., Cohen, D. I., Harding, R. M., Falush, D., Crook, D. W., Peto, T. \& Maiden, M. C. (2005). Hybrid Vibrio vulnificus. Emerg Infect Dis 11, 30-35.

Blake, P. A., Merson, M. H., Weaver, R. E., Hollis, D. G. \& Heublein, P. C. (1979). Disease caused by a marine Vibrio. Clinical characteristics and epidemiology. N Engl J Med 300, 1-5.

Chen, C. Y., Wu, K. M., Chang, Y. C., Chang, C. H., Tsai, H. C., Liao, T. L., Liu, Y. M., Chen, H. J., Shen, A. B. \& other authors (2003). Comparative genome analysis of Vibrio vulnificus, a marine pathogen. Genome Res 13, 2577-2587.

Cipriano, R. C., Pyle, J. B., Starliper, C. E. \& Pyle, S. W. (1985). Detection of Vibrio anguillarum antigen by the dot blot assay. J Wildl Dis 21, 211-218.

Collado, R., Fouz, B., Sanjuan, E. \& Amaro, C. (2000). Effectiveness of different vaccine formulations against vibriosis caused by Vibrio vulnificus serovar E (biotype 2) in European eels Anguilla anguilla. Dis Aquat Organ 43, 91-101.

Cox, A., Zou, W., Gidney, M. A., Lacelle, S., Plested, J. S., Makepeace, K., Wright, J. C., Coull, P. A., Moxon, E. R. \& Richards, J. C. (2005). Candidacy of LPS-based glycoconjugates to prevent invasive meningococcal disease: developmental chemistry and investigation of immunological responses following immunization of mice and rabbits. Vaccine 23, 5045-5054.

Dalsgaard, A., Frimodt-Moller, N., Bruun, B., Hoi, L. \& Larsen, J. L. (1996). Clinical manifestations and molecular epidemiology of Vibrio vulnificus infections in Denmark. Eur J Clin Microbiol Infect Dis 15, 227-232. 
Esteve-Gassent, M. D. \& Amaro, C. (2004). Immunogenic antigens of the eel pathogen Vibrio vulnificus serovar E. Fish Shellfish Immunol 17, 277-291.

Fukuda, Y. \& Kusuda, R. (1985). Vaccination of Yellowtail against pseudotuberculosis. Fish Pathol 20, 421-425.

Gutacker, M., Conza, N., Benagli, C., Pedroli, A., Bernasconi, M. V., Permin, L., Aznar, R. \& Piffaretti, J. C. (2003). Population genetics of Vibrio vulnificus: identification of two divisions and a distinct eelpathogenic clone. Appl Environ Microbiol 69, 3203-3212.

Hitchcock, P. J. \& Brown, T. M. (1983). Morphological heterogeneity among Salmonella lipopolysaccharide chemotypes in silver-stained polyacrylamide gels. J Bacteriol 154, 269-277.

Jolley, K. A., Feil, E. J., Chan, M. S. \& Maiden, M. C. (2001). Sequence type analysis and recombinational tests (START). Bioinformatics 17, 1230-1231.

Kumar, S., Tamura, K. \& Nei, M. (2004). MEGA3: integrated software for Molecular Evolutionary Genetics Analysis and sequence alignment. Brief Bioinform 5, 150-163.

Laemmli, U. K. (1970). Cleavage of structural proteins during the assembly of the head of bacteriophage T4. Nature 227, 680-685.

Maiden, M. C., Bygraves, J. A., Feil, E., Morelli, G., Russell, J. E., Unwin, R., Zhang, Q., Zhou, J., Zurth, K. \& other authors (1998). Multilocus sequence typing: a portable approach to the identification of clones within populations of pathogenic microorganisms. Proc Natl Acad Sci U S A 95, 3140-3145.

Oliver, J. D. (1989). Foodborne Bacterial Pathogens, pp. 569-600. Edited by M. P. Doyle. New York: Marcel Dekker.

Oliver, J. D. \& Colwell, R. R. (1973). Extractable lipids of gramnegative marine bacteria: phospholipid composition. J Bacteriol 114, 897-908.

Park, D. K., Lee, K. E., Baek, C. H., Kim, I. H., Kwon, J. H., Lee, W. K., Lee, K. H., Kim, B. S., Choi, S. H. \& Kim, K. S. (2006). Cyclo(PhePro) modulates the expression of ompU in Vibrio spp. J Bacteriol 188, 2214-2221.

Parmley, S. F., Gross, U., Sucharczuk, A., Windeck, T., Sgarlato, G. D. \& Remington, J. S. (1994). Two alleles of the gene encoding surface antigen P22 in 25 strains of Toxoplasma gondii. J Parasitol 80, 293-301.
Paz, S., Bisharat, N., Paz, E., Kidar, O. \& Cohen, D. (2006). Climate change and the emergence of Vibrio vulnificus disease in Israel. Environ Res (in press) http://www.sciencedirect.com/science/journal/ 00139351.

Provenzano, D., Lauriano, C. M. \& Klose, K. E. (2001). Characterization of the role of the ToxR-modulated outer membrane porins OmpU and OmpT in Vibrio cholerae virulence. J Bacteriol 183, 3652-3662.

Renia, L., Ling, I. T., Marussig, M., Miltgen, F., Holder, A. A. \& Mazier, D. (1997). Immunization with a recombinant C-terminal fragment of Plasmodium yoelii merozoite surface protein 1 protects mice against homologous but not heterologous $P$. yoelii sporozoite challenge. Infect Immun 65, 4419-4423.

Salati, F. \& Kusuda, R. (1985). Vaccine preparations used for immunization of eel Anguilla japonica against Edwarsiella tarda infection. Bull Jpn Soc Sci Fish 51, 1233-1237.

Smith, A. B. \& Siebeling, R. J. (2003). Identification of genetic loci required for capsular expression in Vibrio vulnificus. Infect Immun 71, 1091-1097.

Smith, J. M., Smith, N. H., O'Rourke, M. \& Spratt, B. G. (1993). How clonal are bacteria? Proc Natl Acad Sci U S A 90, 4384-4388.

Sorensen, U. B. \& Larsen, J. L. (1986). Serotyping of Vibrio anguillarum. Appl Environ Microbiol 51, 593-597.

Staden, R. (1996). The Staden sequence analysis package. Mol Biotechnol 5, 233-241.

Tison, D. L., Nishibuchi, M., Greenwood, J. D. \& Seidler, R. J. (1982). Vibrio vulnificus biogroup 2: new biogroup pathogenic for eels. Appl Environ Microbiol 44, 640-646.

Towbin, H., Staehelin, T. \& Gordon, J. (1979). Electrophoretic transfer of proteins from polyacrylamide gels to nitrocellulose sheets: procedure and some applications. Proc Natl Acad Sci U S A 76, 4350-4354.

Webster, A. C. \& Litwin, C. M. (2000). Cloning and characterization of $v u u A$, a gene encoding the Vibrio vulnificus ferric vulnibactin receptor. Infect Immun 68, 526-534.

Wright, A. C., Powell, J. L., Kaper, J. B. \& Morris, J. G., Jr (2001). Identification of a group 1-like capsular polysaccharide operon for Vibrio vulnificus. Infect Immun 69, 6893-6901.

Edited by: P. H. Everest 